\section{Paulo Romano}

Reschilian
CONSTITUIÇÃO DO HABITUS NA PROD $u C ̧ \tilde{O} O$ DO HABITAT ${ }^{1}$

\title{
RESUMO
}

(1) Este artigo, com alterações, faz parte da tese de doutorado $A$ produção de assentamentos precários em São José dos Campos: A favela Nova Tatetuba, um exemplo para análise. defendida na FAUUSP em agosto de 2004
Pretende-se demonstrar como, a partir da abordagem proposta pela sociologia de Pierre Bourdieu, na construção do conceito de habitus, pode-se refletir sobre a produção do hábitat na forma de assentamentos precários qualificados como subnormais ou favelas. 0 objeto de estudo se delimita pelo entendimento de precisar ser considerada, para a análise do fenômeno, uma perspectiva multidimensional, uma vez que a produção de assentamentos precários não se realiza à luz da racionalidade, das normas, parâmetros sociais e urbanísticos vigentes ou estabelecidos com a modernidade. Além disso, pode-se ampliar o espectro da análise para além das categorias propostas pelo materialismo histórico quando na apropriação marxiana da sociologia urbana. Para a análise da expressão desse fenômeno, empreendeu-se o estudo de um assentamento precário no município de São José dos Campos, denominado Nova Tatetuba, removido em 2004 como resultado do programa de erradicação de favelas iniciado pelo município no ano de 2000.

\section{Palavras-Chave}

Hábitat, assentamentos precários, razão prática, habitus, favelas, parâmetros urbanísticos. 
LA CONSTITUCIÓN DEL HABITUS EN LA

PRODUCCIÓN DEL HABITAT

\section{RESUMEN}

Nuestro objetivo es demostrar cómo se puede reflexionar sobre la producción del hábitat en la forma de asentamientos precarios clasificados como subnormales o barriadas, bajo el enfoque propuesto por la sociología de Pierre Bourdieu en la construcción del concepto de habitus. El objeto de estudio se delimita por el entendimiento que, para el análisis del fenómeno, se debe considerar un enfoque multidimensional, ya que la producción de asentamientos precarios no se realiza a la luz de la racionalidad, de las normas, parámetros sociales y urbanísticos vigentes o establecidos en la modernidad. Además, se puede ampliar el espectro del análisis más allá de las categorías propuestas por el materialismo histórico en la apropiación marxista de la sociología urbana. Para analizar la expresión de ese fenómeno, se llevó a cabo el estudio de un asentamiento precario de São José dos Campos, São Paulo, Ilamado Nova Tatetuba, retirado en 2004, en resultado del programa de erradicación de barriadas, iniciado por el municipio en el año 2000.

\section{Palabras clave}

Hábitat, asentamientos precarios, razón práctica, habitus, barriadas, parámetros urbanísticos. 


\section{HABITUS CONSTITUTION IN HABITAT}

\section{PRODUCTION}

\section{ABSTRACT}

Based on the approach suggested by Pierre Bourdieu's sociology, this article demonstrates that the construction of the notion of habitus can reflect on the production of habitat in the form of precarious settlements, such as substandard housing or shantytowns. This study employs a multidimensional perspective, because precarious settlements are not rational and do not follow modern established or existing social and urbanistic rules and parameters. The review will extend beyond the scope suggested by historical materialism under the marxian view of urban sociology. To investigate this phenomenon, the author of this article studied a precarious settlement in the municipality of São José dos Campos, called Nova Tatetuba, which was removed in 2004 as part of a shantytown clearing program established by that city in 2000 .

\section{KEY WORDS}

Habitat, hazardous settlements, practical reasons, habitus, shantytowns, urbanistic parameters. 
(2) Expressão de Francisco de Oliveira, citado em MARICATO, Ermínia. As idéias fora do lugar e o lugar fora das idéias, in ARANTES, Otília; VAINER, Carlos; MARICATO, Ermínia.. A cidade do pensamento único: Desmanchando consensos. Petrópolis: Vozes, 2000.

\section{A Questão Do HÁbitat NA CONTEMPORANEIDAdE}

Investigar a produção de assentamentos precários, especialmente, aqueles qualificados como favelas, é um desafio, na medida em que constitui, na maioria dos casos, tanto para a esfera do poder público quanto para o âmbito acadêmico e profissional "um lugar fora das idéias". ${ }^{2}$

Os trabalhos de investigação mais aprofundada do fenômeno urbano, resultante e gerador dos mecanismos de inclusão precária, que têm nas favelas clara manifestação dessa forma de inclusão, têm sido desenvolvidos pelas administrações municipais mais comprometidas com a construção da justiça social e por pesquisadores, em especial, das áreas de arquitetura e urbanismo, ciências sociais e psicologia.

A reflexão sobre tal processo teve suas bases teórico-metodológicas enunciadas já em Engels, na análise da situação da moradia da classe trabalhadora; especialmente, com a contribuição de Henri Lefébvre deixa de ser concebido como plano de rebatimento da dinâmica propiciada pelas relações de produção de tipo capitalista e é identificado como a base sem a qual essa dinâmica não se realiza. A construção social da paisagem resulta, portanto, do processo de reprodução do capital desencadeado pela disputa pelo controle do território, uma vez que nele se processam as relações de produção as quais sustentam as formas de dominação, segregação e inclusão precária.

Nas últimas duas décadas, estudos sobre a urbanização periférica revelaram a tentativa de construir-se categorias de análise e realizar processos de investigação que incorporassem os aspectos intersubjetivos inerentes às relações sociais experimentadas nas formas de ocupação do território, alicerçando-se nos referenciais da psicologia, da antropologia urbana e das ciências sociais.

A produção teórica sobre as questões sociais e humanas presente nas obras de Pierre Bourdieu (1999, 1997, 1996, 1994, 1972), Michel Certeau (1994), Marc Auge (2000), Boaventura de Souza Santos (2006), além de Lúcio Kowarick (1999) e Gilberto Velho (1999), entre outros, e associada às reflexões relacionadas ao processo de urbanização contemporâneo, encontradas em Félix Guattari (2005), permite constituir um campo de investigação no qual as interfaces formadoras do pensamento sistêmico e complexo emergem diante das questões colocadas para a formulação de análises sobre as formas de ocupação e organização do território, geradores de mecanismos de inclusão precária.

$\mathrm{Na}$ medida em que sustento que o entendimento dos problemas urbanos é percebido pela compreensão dialética entre as formas de expressão da condição humana no território, resultantes da maneira como os diferentes estratos sociais se apropriam dele e da riqueza nele produzida e, a partir desse território, analisar a questão da desigualdade socioambiental urbana à luz das categorias espaço, território, paisagem, urbanização, sociedade, pode significar um descolamento da condição humana que materializa no e a partir desse espaço e desse processo. 
(3) Concepção desenvolvida por Pierre Bourdieu e analisada em ORTIZ, Renato (Org.). Pierre Bourdieu: Sociologia. São Paulo: Ática, 1983.
O objeto a ser investigado é a forma de constituição do hábitat em condições classificadas como "subnormais", e por que esses mesmos se tornam mecanismos de inclusão precária, dentro de uma lógica que pode ser entendida pelos referenciais propostos pelos campos de conhecimento configurarem uma base multidisciplinar.

O enfoque pretendido para analisar a produção de assentamentos precários busca, nos estudos de antropologia urbana, na teoria praxiológica ${ }^{3}$, na psicologia ambiental e comunitária, elementos para sustentar as hipóteses a serem formuladas.

A fundamentação que configura a análise multidimensional proposta parte do pressuposto de a produção do hábitat poder ser analisada a partir dos processos microssociais que se desenvolvem no cotidiano e a partir das estratégias de reprodução associadas à constituição do hábitat nas condições precárias.

Entende-se ser necessário construir indicadores e categorias de análise que identifiquem quais as referências culturais (gosto, estilo de vida e representação simbólica, por exemplo) e os elementos intra-subjetivos (individuais e comunitários) a condicionarem o tipo de inserção que famílias e grupos sociais logram nas condições habitacionais, ambientais e sociais em que vivem, além dos próprios condicionantes materiais, inerentes aos estratos sociais os quais habitam em condições precárias.

A compreensão dessa dinâmica vai além da dimensão material propriamente dita e insere-se na esfera subjetiva e na compreensão do desenvolvimento de estratégias de reprodução que pressupõem um campo de representações as quais ultrapassam o domínio da lógica, dos determinismos e das regras.

Nesse sentido, tomando-se como referência os conceitos de fixação e mobilidade, Paoliello (2000), pretende-se analisar a produção do hábitat nessas condições como uma iniciativa deslocada da racionalidade urbanística consagrada pelos parâmetros contemporâneos. A tipologia do hábitat construído e, por vezes, "melhorado" ao longo do tempo, ainda que condicionado pela precariedade das limitações materiais, parece seguir um "padrão" de agenciamento espacial cujos arranjos podem evidenciar um contraponto ao habitus urbano vigente.

O que se pretende verificar é a existência de uma cultura que não se condiciona, a princípio, pelos parâmetros da modernidade e revela hábitos de morar e de inserir-se no ambiente de forma tão precária quanto o grau de precariedade a que estão submetidos.

A pesquisa, orientada para a construção de evidências da existência de um habitus, ou seja, um modo de vida do morador de assentamentos precários e qualificado por uma série de atributos e práticas específicas foi estruturada pelas referências da metodologia qualitativa, uma vez que, no universo da pesquisa em questão, além dos indicativos socioeconômicos, objetivos e quantitativos, fez-se necessário investigar os indicativos subjetivos, aqui entendidos como relacionados ao campo da cultura.

Cabe destacar que pelo mesmo procedimento metodológico adotado abre-se um campo para a investigação, dentro da constituição do denominado modo de vida na favela, das expressões intra-subjetivas, para as quais a contribuição da psicologia social é fundamental.

A partir da corrente do materialismo histórico, autores como Lefébvre, Castells, Lojkine, Gottdiener, Lipietz e Harvey contribuíram para a análise do processo de urbanização capitalista engendrado como mecanismo de construção social do espaço e da paisagem. 
(4) Dentre as publicações da obra de Bourdieu, valemo-nos especialmente de BOURDIEU, Pierre. A economia das trocas simbólicas. São Paulo: Perspectiva, 1999; BOURDIEU, Pierre (1996). Razões práticas: Sobre a teoria da ação. Tradução de Mariza Corrêa. 4. ed. Campinas: Papirus: BOURDIEU, Pierre (Coord.). A miséria do mundo, 1997. Vários tradutores. Petrópolis, Vozes; PINTO, Louis.

Pierre Bourdieu e a teoria do mundo social.

Tradução de Luiz Alberto Monjardim. Rio de Janeiro: FGV, 2000; MICELI, Sergio. A força do sentido. BOURDIEU, Pierre. A economia das trocas simbólicas. São Paulo, 1999, p. VII-LXI; ORTIZ, Renato (Org.). Pierre Bourdieu: Sociologia. São Paulo: Ática, 1999.

\section{Pierre bourdieu E A teoria dA AÇÃo}

O estudo dos pressupostos teóricos formulados por Pierre Bourdieu ${ }^{4}$, em sua densa produção, pode ser apropriado para o universo das reflexões sobre as formas de ocupação territorial que resultam em assentamentos precários, por meio da epistemologia que fundamenta o conhecimento praxiológico no qual se estrutura o conceito de habitus.

Entende-se que a contribuição de Bourdieu constituiu-se em uma abertura para o campo sociológico - estruturador de inúmeras análises sobre os processos de urbanização - pois possibilitou a constituição epistemológica que articula dois pressupostos, em tese antagônicos: o objetivismo e a fenomenologia, ao qual Bourdieu denominou conhecimento praxiológico (ORTIZ, 1983).

$\mathrm{Na}$ medida em que Bourdieu compreende a ação humana em sociedade não existir como totalidade, mas "como intersubjetividade que tem origem na primeira ação do sujeito" (ORTIZ, 1983), é possível conceber uma abordagem que supere os limites do objetivismo e abra perspectivas para incursões metodológicas a catalisarem outras concepções que incorporem os aspectos dessa intersubjetividade.

O conceito central extraído da obra de Bourdieu, o conceito de habitus, bem como as relações estabelecidas entre as estratégias de reprodução e o campo social em que se inserem, possibilita construir-se uma abordagem que complemente os estudos sobre urbanização e inclusão precária produzidos até então. Na medida em que se vale do conceito de habitus, abre-se um campo para a investigação, nos termos de Bourdieu, de uma "razão prática", sem passar pela racionalidade das regras ou normas.

Os estudos de Bourdieu podem ser entendidos como uma tentativa de tratar a questão da mediação entre o agente social e a sociedade (ORTIZ, 1983). Significa dizer que Bourdieu identifica dois tipos de conhecimento formulados a partir de duas premissas antagônicas: o objetivismo e a fenomenologia.

Segundo Miceli (1999, p. VIII), Bourdieu distingue duas posturas principais diante das diversas orientações que identificam o sistema de fatos e representações e são recobertos pelo que abrange a cultura. Por um lado, as questões colocadas na problemática kantiana a encontrar suas origens em Cassirer, Sapir, inclusive Durkheim e Levi-Strauss, considera a cultura - e por extensão todos os sistemas simbólicos, como a arte, o mito, a linguagem, etc. - em sua qualidade de instrumento de comunicação e conhecimento responsável pela forma nodal de consenso, qual seja, o acordo ao significado dos signos e quanto ao significado do mundo. De outro, considera-se a cultura e os sistemas simbólicos, em geral, como um instrumento de poder, isto é, de legitimação da ordem vigente. Refere-se, nesse caso, à tradição marxista e à contribuição de Max Weber que, a despeito dessa aproximação, encontram-se separados por outros tantos motivos.

No conhecimento praxiológico de Bourdieu, a dimensão das representações simbólicas ganham uma conotação a qual supera a concepção materialista que atribui aos aspectos simbólicos um caráter alegórico.

Para Bourdieu, deve-se pensar a prática como algo distinto da pura execução de uma norma social, configurada em um sistema de relações objetivas determinantes de um modelo de organização social. Bourdieu busca, na idéia 
(5) “Na Argélia, nos anos 50 e 60, indivíduos são arrancados do universo rural que Ihes era familiar e vêem-se lançados no universo da economia urbana e capitalista, diante do qual estavam desarmados: não só eles não podem elaborar estratégias coerentes, como tendem a explicar seu destino social pela fatalidade ou acaso.", op cit., PINTO, Louis. Pierre Bourdieu e a teoria do mundo social. Rio de Janeiro: FGV, p. 38, 2000. escolástica de habitus, a mediação que possibilita estabelecer a relação entre as estruturas objetivas e a prática que orienta as ações dos atores sociais.

As reflexões e conceitos encontrados na produção de Bourdieu, no que concerne à teoria do habitus, tiveram suas bases constitutivas no capital teórico da antropologia estrutural e nas pesquisas realizadas pelo autor nas décadas de 1950 e 1960 na Argélia, em um contexto no qual se assistia ao êxodo rural no país e à tentativa de afirmação da economia urbana. ${ }^{5}$

Segundo Bourdieu, pode-se identificar uma relação entre os espaços das posições sociais e os estilos de vida, cujas tomadas de posição são propiciadas pela intermediação do espaço de disposições habitus. De acordo com Bourdieu (1996), para cada classe de posições corresponde uma classe de habitus (ou de gostos) produzidos pelos condicionamentos sociais associados à condição correspondente e pela intermediação desse habitus e de suas capacidades geradoras, um conjunto sistemático de bens e propriedades, vinculadas entre si por uma afinidade de estilo.

Nas palavras de Bourdieu (1996), "Os habitus são princípios geradores de práticas distintas e distintivas - o que o operário come, e, sobretudo sua maneira de comer, o esporte que pratica e sua maneira de praticá-lo, suas opiniões políticas e sua maneira de expressa-las diferem sistematicamente do consumo ou das atividades correspondentes do empresário industrial" (BOURDIEU, 1996, p. 20-21).

O espaço social, a que se refere Bourdieu, como elemento diferenciado de classe, constitui-se no ponto no qual cada indivíduo ou grupo social se situa no mundo social, e, pelas condições aí alocadas, possibilita uma perspectiva sobre a realidade mediada pela posição assumida a partir desse ponto, que é um ponto de vista.

Bourdieu (1996) afirma que a proximidade dos agentes nesse espaço social predispõe à aproximação (pelas disposições, habitus e seus gostos).

Nesse sentido, ao propor o conceito de espaço social, ao invés de classe, Bourdieu estabelece, segundo Pinto (2000): "A unidade de análise pertinente, nesse caso, não é o sistema de identidades coletivas chamadas de classes, e sim o conjunto de posições objetivas determináveis por uns poucos princípios, entre os quais figuram notadamente: a posse daquilo que, em uma determinada formação social, vem a ser o capital (no caso, o capital econômico e o capital cultural) e o volume de capital possuído." (PINTO, 2000, p. 96)

Associada à noção de habitus, posteriormente Bourdieu estabelece a noção de campo, que, para o autor, constituiu uma autonomia, perante certas determinações consideradas estruturais e nele podem se instaurar conflitos em relação ao que conforma a legitimidade das reproduções do mundo social.

O simbólico, na acepção de Bourdieu, apresenta-se para suas reflexões como objeto dotado de autonomia e fundamenta-se, segundo a análise de Pinto (2000), em três redes conceituais distintas:

"Simbólico é entendido primeiramente como atividade de construção cognitiva (sentido) por oposição à ação política de transformação ou conservação do real (força); depois, como subjetivo (representação) por oposição a objetivo (estrutura); e finalmente, como modo de excelência (humana, pessoal) por oposição a valor de mercado (economia)." (PINTO, 2000, p. 197)

Para entendimento das questões que envolvem uma "aplicabilidade" das concepções de Bourdieu, dois conceitos ou elementos são fundamentais: a noção 
(6) Ver BOURDIEU, Pierre. Razões práticas: Sobre a teoria da ação. Campinas: Papirus, 1996. de estratégia de reprodução e a idéia de família como o núcleo por meio do qual as relações do mundo social se constroem e reproduzem.

Inicialmente, falar em família significa, para Bourdieu (1996, p. 127), tratar de uma categoria como princípio coletivo de construção da realidade coletiva, no qual esse princípio de construção é um dos elementos constitutivos do habitus, uma estrutura mental que, tendo sido inculcada nas mentes socializadas de certa maneira, é, ao mesmo tempo, individual e coletiva, tal qual uma lei tácita (nomos) da percepção e da prática que fundamenta o consenso sobre o sentido do mundo social (e da palavra família em particular), fundamenta o senso comum.

Ressalta-se que a família como categoria social objetiva é, para Bourdieu, o fundamento da família como categoria social subjetiva, categoria mental associada a representações e ações (casamentos, por exemplo) que contribuem para reproduzir a categoria social objetiva. Para o autor, esse é o círculo de reprodução da ordem social. ${ }^{6}$

Configurando o cenário que constitui o universo das reflexões de Bourdieu ( habitus, campo, estilo de vida, família, capital simbólico, estratégias de reprodução, entre outros), pretendo demonstrar a possibilidade de reconhecer, na favela, elementos explicativos ou representativos de uma teoria da ação na qual Bourdieu propõe:

"A teoria da ação que proponho (com a noção de habitus) implica dizer que a maior parte das ações humanas tem por base algo diferente da intenção, isto é, disposições adquiridas que fazem com que a ação possa e deva ser interpretada como orientada em direção a tal ou qual fim, sem que se possa, entretanto, dizer que ela tenha por princípio a busca consciente desse objetivo." (BOURDIEU, 1996, p. 164)

Tomando-se como referência a abordagem praxiológica e identificando o conceito de habitus como elemento que opera a mediação entre o ator social e o campo social, entende-se ser possível a aplicação da epistemologia proposta por Bourdieu para a compreensão dos fenômenos urbanos que produzem as formas de inclusão precária no território das cidades.

\section{O CONCEITO DE HABITUS E A PRODUÇÃO DO ESPAÇO}

Partindo-se da idéia de a cidade expressar, em sua organização territorial, elementos não exclusivamente da materialidade visível, pode-se percebê-la sob o fundamento de sua complexidade fenomenológica.

Essa abordagem não significa deslocar a percepção da cidade como cenário constitutivo do mercado e insere-se na dimensão objetiva das questões socioeconômicas. As afirmações de Amaral (1992, p. 39) apontam que, pensar a cidade como construção simbólica de determinados grupos (inclusive o grupo dos que estudam a cidade) possibilita ver que ela não rejeita seu papel de mercado, encontrando sua melhor definição, provavelmente, nesse termo, pois, além de mercado de trabalho, de trocas materiais, é o lugar onde os grupos efetuam também - e especialmente - suas trocas simbólicas.

A análise sobre os fenômenos urbanos, estruturada a partir do percurso de Bourdieu (1972), pode ser percebida, segundo Ortiz (1983), como sendo um processo no qual "Cada agente quer saiba ou não, quer queira ou não, é produtor e 
I44 (7) Conceito desenvolvido por Pierre Bourdieu e apresentado ao longo deste trabalho. reprodutor de sentido objetivo porque suas ações e suas obras são produto de um modus operandi do qual ele não é o produtor e do qual ele não possui o domínio consciente; as ações encerram, pois, uma 'intenção objetiva', como diria a escolástica, que ultrapassa sempre as intenções conscientes" (ORTIZ, 1983, p. 182).

Analisar as formas de ocupação do território, geradoras de assentamentos humanos precários é analisar essa prática como uma ação relativa à produção do hábitat, contextualizado pelo habitus ${ }^{7}$ que constitui a maneira pela qual determinados grupos sociais contribuem para a produção da paisagem urbana que se qualifica como precária.

Se relacionarmos que há um modus operandi a produzir a força motriz do fenômeno da urbanização capitalista, entendemos que, na perspectiva da organização do hábitat no território, evidencia-se a associação que Bourdieu (1993) faz entre "gostos de classe e estilos de vida" ao afirmar que às diferentes posições no espaço social correspondem estilos de vida, sistemas de desvios diferenciais que são a retradução simbólica de diferenças objetivamente inscritas nas condições de existência.

Sob essa ótica, pode-se afirmar que o entendimento de Bourdieu (1983) sobre a dinâmica que constitui o "estilo de vida' pode ser aplicado na análise do ambiente construído, pois 'o estilo de vida é um conjunto unitário de preferências distintivas que exprimem, na lógica específica de cada um dos subespaços simbólicos, mobília, vestimentas, linguagem ou héxis corporal, a mesma intenção expressiva, princípio da unidade de estilo que se entrega diretamente á intuição e que a análise destrói ao recortá-lo em universos separados'".

A questão central para a qual se deve atentar é tratada por Paoliello (2000) ao afirmar que entre as classes populares, muitas vezes se notam, em suas representações e práticas de paisagem, espaço e natureza, entrecruzados e/ou em oposição ao que, eventualmente, trazem de uma memória anterior, e com freqüência rural, ou da experiência migratória, influxos da mídia, de valores e de uma estética da cultura globalizada, apropriados em contextos específicos e com sentido particular. Ainda decorrente da análise de Paoliello, observa-se que a experiência migratória e a submoradia são as manifestações mais agudas desses processos e, para compreendê-los, é fundamental ter em foco as disputas pelo espaço, em particular o urbano, suas apropriações diversas e conflitantes no curso dessas disputas, manifestas em estratégias de espacialização - fixação e mobilidade - que vão dando a feição, aparentemente caótica, à cidade e ao seu entorno. Segundo a autora citada, ao focalizarmos as estratégias e seus agentes, em especial, podemos revelar dimensões decisórias e subjetivas da ação social, importante para a participação pública nos projetos de requalificação do espaço, sem cairmos no estritamente fenomenológico.

Nesse sentido, o entendimento dos mecanismos constitutivos dos assentamentos precários passa pela compreensão de como se configuram, no hábitat, em sua espacialidade e forma de inserção no ambiente construído, as estratégias de reprodução que Bourdieu (1994) sugere como sendo um quadro das grandes classes de estratégias de reprodução: estratégias de investimento biológico, entre as quais as mais importantes são as de fecundidade e as profiláticas; as estratégias sucessórias, as estratégias de investimento econômico, articuladas com as de investimento social e matrimoniais; as estratégias de investimento simbólico e, por fim, as estratégias educativas. 
(8) Citado em JODELET, Denise. "A cidade e a memória" in DEL RIO, Vicente et al. O projeto do lugar. Rio de Janeiro, contracapa.
Se o ideário que sustenta os projetos de transformação do ambiente construído, dentro do conjunto de ações para o alcance do direito à cidade, à moradia, à arquitetura e à dignidade da condição da vida humana nas cidades pressupõe a participação popular, planejamento e orçamento participativo, entendemos que ainda há uma lacuna na compreensão do nível de representações que indivíduos, famílias e grupos sociais fazem de si, de suas perspectivas.

Parte-se do pressuposto que a investigação do cotidiano pode fazer emergir indicadores para a construção de categorias de análise sobre o ambiente construído nos assentamentos precários e orientar levantamentos de campo nos quais se possa estabelecer a relação entre a teoria praxiológica de Bourdieu e as formas de reprodução de assentamentos humanos.

Se a ação humana sobre o ambiente e a inerente disputa pelo controle do espaço produzido, inclusive como estratégia de dominação social e acumulação de capital, traduz-se na materialização de formas e mecanismos de configuração do espaço construído, no que se refere à sua forma de organização e apropriação, é possível pensar como Suzanne Seagert, que analisa o meio ambiente, especialmente o espaço construído, como material, artefato e matriz ${ }^{8}$.

Em conseqüência, a análise do cotidiano e das estratégias de reprodução remete-nos às afirmações de Certeau, quando percebe que não se pode falar em estratégia ou "intenção estratégica", mas de ações a terem mais sentido pelo que se faz do que pelo que se sabe.

Derivada dessa reflexão, ao pensar-se a moradia nesse contexto, Certeau (1994) afirma: "A casa dá ao habitus a sua forma, não, porém o seu conteúdo. Aliás, a argumentação de Bourdieu procura não tanto indicar essa realidade, mas antes mostrar a necessidade e as vantagens de sua hipótese para a teoria. Deste modo, o habitus se torna lugar um lugar dogmático, caso se entenda por dogma a afirmação de um real de que o discurso necessita para ser totalizante."

(CERTEAU, 1994, p. 124)

\section{A favela nova tatetuba: referênCia para anÁlise}

O assentamento Nova Tatetuba, outrora denominado "morro do Regaço" e também conhecido como "Olaria Zé Ferreira" e "Morro da Serveng" caracterizouse, para efeito da pesquisa realizada, como um lugar no qual puderam ser evidenciadas as hipóteses levantadas a respeito das razões pelas quais se desenvolvem determinados hábitos ou formas de vida quando se investiga moradores de favelas.

O assentamento se localizava na avenida Juscelino Kubitschek, bairro Nova Tatetuba, em São José dos Campos.

A ocupação do terreno no qual se localizava o assentamento é originária da construção de moradias para famílias que trabalhavam na olaria do senhor José Ferreira há cerca de 40 anos, aproximadamente. Com a desativação da olaria, cinco famílias com créditos trabalhistas permaneceram no local, dando início ao que viria ser 0 assentamento.

Considero emblemático o estudo da favela Nova Tatetuba, pois o processo que a envolve há quase uma década indicou tendências de permanência e 
(9) Cabe salientar que a favela Nova Tatetuba foi objeto de projeto de reurbanização na gestão da prefeita Ângela Guadagnin (1993-1996) apresentado aos moradores do assentamento na época. ruptura, às quais foram submetidos os moradores desse assentamento e o quanto as perspectivas de consolidação e estabilização conviveu permanentemente, especialmente nos últimos cinco anos, com a iminência de desocupação.

Ainda que se pudesse avaliar a existência de um habitus da favela em qualquer outro assentamento, alguns indicadores foram relevantes para investigar a Nova Tatetuba: situar-se em uma área, avaliada pelo Instituto de Pesquisas Tecnológicas - IPT, como área de risco; localizar-se em um terreno particular, objeto de espólio inserido em região de valorização imobiliária crescente; situar-se nas proximidades do córrego Cambuí, qualificando-se, dessa forma, como área de manancial; constituir-se como favela há mais de 20 anos e abrigar, aproximadamente, 223 famílias, segundo dados cadastrais da prefeitura de 19992000.

Ao analisar o cenário das tendências do processo de urbanização do município de São José dos Campos na última década, particularmente, observando-se os indutores gerados pela política habitacional na administração do prefeito Emanuel Fernandes (PSDB), 1996-2004, identifica-se, no plano de erradicação de favelas, associada à construção de moradias, a evidência de uma política de inclusão precária, uma vez que o perfil dessa política é deslocar os moradores de favela para as regiões sul e leste da cidade, consagrando a segregação da população de baixa renda9 .

A gradativa transferência de moradores de assentamentos precários dentro dos programas de erradicação de favelas para as regiões sul e leste da cidade, formando-se o que se poderia chamar de bolsão de assentamentos populares contribuiu para configurar uma organização do território, marcada pela precarização das condições habitacionais e urbanas nessas regiões.

A escolha da favela Nova Tatetuba para estudo deveu-se ao fato de, nesse assentamento, constituir-se o único núcleo de resistência até então, à idéia de transferir-se para o residencial Jardim São José. No núcleo de resistência havia, inicialmente, 70 famílias, número que se reduziu para, aproximadamente, 45 famílias após a primeira ação de remoção da favela realizada em 30 de dezembro de 2003.

A ausência de perspectiva, incerteza, desconfiança, e, ao mesmo tempo, crença, esperança e expectativa de conquistar o direito de permanecer no local, tornou as famílias que resistiram, para efeito das questões que se discutem neste trabalho, a prioridade da investigação realizada.

Após a remoção definitiva de 7 de janeiro de 2004, as famílias foram abrigadas na sede da ONG O Novo no Poder, em São José dos Campos, apoiada pelo vereador Mauro Kano, do Partido dos Trabalhadores, para, posteriormente, invadirem e ocuparem uma área desocupada pertencente à extinta Estrada de Ferro Central do Brasil, permanecendo no local até o presente momento.

Tais ocorrências podem sugerir elementos para a compreensão por essa "opção" em viver em condições nas quais a precarização do hábitat - mesmo com a expectativa de ter sido por curto período de tempo - seja adotada em detrimento da ocupação de novas moradias no conjunto construído pelo poder público.

Partindo-se dos dados fornecidos pela prefeitura de São José dos Campos, de visitas de reconhecimento ao local, de informações obtidas junto das lideranças da comunidade e tomando como referência informações da Central de Movimentos Populares - C.M.P., foi estruturada a pesquisa de campo de acordo com 
pressupostos da metodologia qualitativa. Utilizou-se questionários individuais e constituiu-se grupos focais.

O questionário utilizado como guia para estabelecer a entrevista semiestruturada partiu de alguns pressupostos por meio dos quais entendi ser possível obter indicativos ao analisar as respostas formuladas pelos participantes da pesquisa. As hipóteses que fundamentaram as questões propostas foram:

- As experiências de vida familiares e nas moradias anteriores condicionam, de certo modo, a "opção" pela favela como alternativa possível de moradia e sobrevivência, uma vez que, ocupando determinado lugar no território, próximos de alcançar possibilidades de trabalho e renda e sem ônus como o custo da moradia, pode-se criar meios de sobrevivência nas cidades cuja oferta de trabalho poderia ser melhor;

- o agenciamento do espaço do hábitat indica uma forma de apropriação do território na qual é possível adaptar as formas de subsistência e sobrevivência próprias de uma inserção precária, e, por vezes, distante do ideal de urbanidade;

- a habitação se constitui na expressão de um modo de ser no mundo;

- quer seja pelo lugar que ocupa na escala social, quer seja pelo lugar que ocupa no território;

- os tipos de atividades executadas para obtenção de renda, realizadas na favela, podem ser possibilitados pela existência de uma precarização e informalidade das condições de trabalho e configuram o campo das estratégias de sobrevivência;

- os hábitos culturais (higiene, saneamento, alimentação, organização do espaço, meios de sobrevivência) transitam entre o rural e o urbano, este último mais como possibilidade do que como realidade;

- a ausência de consciência sobre a importância das questões ambientais faz com que alguns moradores sejam vítimas das condições do meio onde vivem e, ao mesmo tempo, contribuam para a degradação desse mesmo ambiente.

O roteiro para dinamização dos grupos focais foi elaborado procurando abordar a questão do hábitat na favela e verificar se poderiam ser confirmadas as respostas elaboradas nas entrevistas. As hipóteses formuladas para estabelecer 0 diálogo nos grupos pretenderam propiciar reflexão e narrativa sobre as questões:

- A qualidade da moradia está associada à percepção ou compreensão do lugar que cada família acredita ocupar na vida e a consciência de sua condição material e social;

- o reconhecimento da cidade como lugar do exercício da cidadania contribui para a opção de manter-se na favela como possibilidade de sobrevivência e alcançar outra condição de inserção urbana quando puder.

Ao analisar o conteúdo das respostas, tanto das entrevistas quanto da discussão dos grupos focais, pode-se identificar seis indicativos que traduzem o processo de inserção e permanência na favela:

1. Associa-se às origens familiares e à migração, pois a maioria dos entrevistados advém de outros estados e apresenta um histórico de pobreza na família de origem.

2. Relaciona-se com o primeiro hábitat na favela, cujas condições eram muito precárias, e essa experiência indica que a superação para outro estágio de 
moradia é percebida como melhoria das condições de vida e perspectiva de afirmação.

3. Vincula-se aos investimentos na moradia, de forma individual e gradativa, na perspectiva de conseguir concluir a casa ideal dentro do contexto de incertezas em que se inserem, especialmente em relação à dependência dos desígnios do poder público.

4. Relaciona-se à forma pela qual os moradores com hábitat consolidado desenvolveram estratégias de sobrevivência possibilitadas pela forma de apropriação do território.

5. Constitui-se na identificação com a favela como lugar de possibilidade de inserção na cidade, apesar do estigma e dos preconceitos.

6. Relaciona-se às expectativas de futuro.

A primeira referência obtida dos entrevistados é relacionada a um histórico de pobreza, configurado por problemas de emprego no lugar de origem ou procedência anterior à vinda da favela, bem como condições de habitação não menos precárias que as da favela, muitas delas na zona rural. Isso significa a experiência de vida em lugares sem infra-estrutura ou saneamento ou fora do ambiente urbanizado. Além disso, devido a esse contexto, o grau de escolarização é baixo e, invariavelmente, as habilidades são para trabalhos manuais, especialmente na construção civil, vigilância e serviços domésticos.

Observa-se, por meio do conjunto de depoimentos obtidos, ser possível reafirmar a existência de uma condição de vida própria de assentamentos precários que seja indicativa de uma forma de organização espacial e de sobrevivência associada a um estilo de vida ou habitus. A experiência de vida anterior à favela, condicionada por contextos de precariedade e pouca inserção na dinâmica urbana em municípios de maior porte, implicou em uma prática de vida na qual a permanência do cotidiano e a emergência do tempo fizeram com que a apropriação dos espaços ocorresse à margem das normativas jurídicourbanísticas vigentes. A tendência, tanto por razões culturais como por razões de sobrevivência, em fazer criação de animais ou plantar hortas e pomares, indica um modo de apropriar-se de meio, diferentemente do trabalhador urbano, já condicionado pelo modo de vida tipicamente citadino.

Diante das perspectivas de vida que passam a configurar-se, verificou-se, no contato com a maioria das pessoas que habitavam o assentamento Nova Tatetuba, um desejo de melhoria, porém, que fosse realizada dentro das condições de vida que se construiu e nos parâmetros que parecem ter sido estabelecidos, ou seja, a continuidade no lugar, conquista de título de propriedade para investimento na moradia, manutenção da individuação da moradia e provimento de infra-estrutura.

\section{CONSIDERAÇÕES FINAIS}

A existência de assentamentos precários qualificados por favelas em países como o Brasil, situados na periferia do capitalismo, pode ser entendida como parte de um processo multicausal associado à dinâmica geradora dos mecanismos inerentes à urbanização brasileira no contexto da inserção do país na economia-mundo em sua história. 
Evidenciou-se, historicamente na sociedade brasileira, uma relação entre a apropriação da renda e da terra, percebidas como instrumento e mecanismo de controle sociopolítico, constitutivo da base territorial sobre a qual as perspectivas e a garantia da reprodução do capital se consolidaram.

A urbanização brasileira, caracterizada pela segregação espacial, foi a marca reveladora da forma pela qual as elites se apropriaram do território no processo de construção social da paisagem urbana. Além disso, especialmente no período no qual se acelera o processo industrial no Brasil, a partir da década de 1930, com os projetos desenvolvimentistas de 1950 e da fase do poder militar, o papel do Estado passa a ser fundamental nas diretrizes de organização do território.

A modernização brasileira, alicerçada no binômio urbanização e industrialização, estruturou-se sob bases conservadoras, ou seja, mantendo quase inalterada a forma de organização da propriedade rural e concentrando a terra urbana nas mãos das elites. A formação do contingente dos trabalhadores urbanos, em que pesem as políticas trabalhistas de Vargas, não possibilitou a estruturação da sociedade do trabalho na qual se garantisse o alcance ao consumo de bens e serviços, privados ou públicos.

Dessa forma, a tendência à expansão urbana periférica, originada da relação de elementos como o modelo de desenvolvimento do país organizado em torno do parque industrial do sudeste, a desestruturação do campo e a conseqüente atração de mão-de-obra para as cidades, a falta de oferta de moradia no mercado imobiliário formal e os baixos salários associados à crescente queda na oferta de emprego, configuraram o cenário no qual a expansão de assentamentos precários foi inevitável.

As evidências surgidas no processo de investigação, especialmente junto dos participantes da pesquisa que fazem parte do grupo de famílias as quais resistiram em transferir-se para as residências construídas pela prefeitura, com financiamento do BID, apontam para a necessidade de compreensão de elementos a constituírem o plano da objetividade, da materialidade, da escassez e do plano de uma racionalidade pautada pela convivência de hábitos urbanos e de sobrevivência, desenvolvidos na experiência de vida não-urbana e na precariedade anterior à transferência para a favela.

O entendimento dessa racionalidade passa pela investigação de componentes subjetivos, delimitados, neste trabalho, dentro dos aspectos da manifestação de hábitos e visões de mundo, no campo cultural, e pela tentativa de evidenciar como as condições de precariedade vão desenvolvendo crenças sobre as próprias possibilidades de vida e consolidando certas práticas de vida.

A primeira evidência encontrada para demarcar a "opção" pela favela relaciona-se a um histórico de precariedade e de pobreza experimentado em lugares nos quais as famílias viviam. Além disso, uma rede relacional, de parentesco, de amizades ou conhecimentos torna a busca pela tentativa de superação da precariedade vivida no momento em que se decide mudar para outra cidade ou para uma cidade, com mais possibilidade de garantir a sobrevivência da família.

Deve-se atentar para o fato de a maioria dos moradores da favela serem oriundos de cidades com menos perspectiva de crescimento e oportunidades ou residirem na zona rural. Significa dizer que seus hábitos de vida não se condicionavam no que se refere aos meios de subsistência, tipologia da moradia, 
acesso a equipamentos urbanos, organização do espaço da casa e do território, aos parâmetros das regiões de características metropolitanas, como é o caso de São José dos Campos.

O segundo elemento a ser verificado é a forma pela qual muitos habitantes da favela, ainda que na incerteza da transitoriedade, constituíram estratégias de superação das adversidades, sendo a moradia o primeiro e estruturador estágio de afirmação da garantia da mínima condição de vida. Do primeiro barraco ou cômodos à transformação da moradia que muitos conseguiram realizar por conta própria e por meio da autoconstrução, a forma de apropriar-se do espaço foi determinante para a consolidação da vida na favela.

Nesse sentido, o agenciamento do espaço do hábitat indica uma forma de apropriação do território na qual é possível adaptar as formas de subsistência e sobrevivência próprias de uma inserção precária, e, por vezes, distante do ideal de urbanidade.

Deve-se destacar que construção ou ocupação de uma unidade de habitação na favela já inaugura uma estratégia de sobrevivência a qual, como abrigo e mecanismo de demarcação do território, indica as possibilidades de garantir o assentamento humano no lugar.

O terceiro elemento está associado à relação entre a forma de ocupação do espaço no qual se insere a moradia e os ganhos secundários no que se refere à sobrevivência, que, no caso da favela Nova Tatetuba, além das vantagens locacionais identificadas, foram possibilitados pela característica do próprio local no qual foi possível para muitas famílias criar animais, hortas e pomares. A maneira pela qual se deu a apropriação do território e a organização da vida em torno desse hábitat não se parametriza nas formas de vida consagradas para trabalhadores urbanos, moradores quer de conjuntos de apartamentos, quer em residências unifamiliares de área construída restrita e terreno com dimensões mínimas. Soma-se a tais condições o trabalho com a reciclagem de resíduos sólidos à qual alguns chefes de famílias se dedicavam para complementar a renda. Para tornar possível dedicar-se a essa atividade, a localização da favela próxima do centro da cidade e a existência de espaço no terreno das casas para armazenagem e seleção do material a ser vendido foram fundamentais.

No caso em estudo, verifica-se que os determinantes físico-geográficos e a seqüência de ocupação da áreas, próximas ao rio Cambuí, permitiram o desenvolvimento de práticas e formas de vida consagradas no meio rural e na memória cultural de um conjunto significativo de oradores que se valeram da criação e plantação para contribuir com a subsistência da família. Nesse contexto, a convivência com animais de criação no hábitat indica a existência de um estilo de vida que configura um habitus constituído no contexto desse modo de vida.

A quarta constatação evidencia o entendimento, de forma consciente ou percebido pela forma como os moradores se expressaram, do lugar que ocupam na cidade, estando na favela, e suas pretensões. A identificação dos estigmas e preconceitos que os envolvem, mas não necessariamente os fazem querer deixar o lugar, indica haver uma "razão prática" que os faz perceber as vantagens locacionais, mas também os faz entender a permanência nesse lugar, como possibilidade de conquista de um espaço na cidade, consideradas as expectativas de regularização da propriedade e da ocorrência de investimentos em infraestrutura. 
A constatação propiciada pela investigação realizada é que se torna necessário entender a favela como um lugar não-determinado pela ausência; ausência de infra-estrutura, de equipamentos, de segurança, entre outras.

Com a pesquisa realizada pretendi demonstrar que a favela, na perspectiva dos poderes públicos e de setores da sociedade, é percebida como um problema a ser sanado, ainda que seja incontestável a precariedade a marcar a natureza desses assentamentos. Mas, quando se percebe a favela como um problema, pensa-se em soluções habitacionais urbanas, sejam conservadoras, sejam consideradas progressistas, que, invariavelmente, fundamentam-se na lógica da urbanística moderna, na idéia de a cidadania associar-se a uma noção de urbanidade que passa pela configuração do hábitat dentro de determinados parâmetros e do ideal de vida que percebe a moradia como abrigo produzido em série.

Por fim, entendo que pensar em política de habitação de interesse social é refletir sobre a concepção de família e a organização da moradia da população moradora de favelas, especialmente provenientes de contextos de precarização e de processos migratórios.

Dessa forma, para se construir uma abordagem sobre a constituição de assentamentos precários, é necessário associar os seguintes pressupostos:

- A existência de assentamentos precários resulta de um processo de inclusão precária produzida pela dinâmica da urbanização capitalista;

- a existência desses assentamentos opõe, por assim dizer, um habitus urbano sustentado na racionalidade da urbanística moderna e nas normativas legais da lógica capitalista e um habitus decorrente de estratégias de reprodução dentro dessa lógica, mas que se parametrizam na emergência da "razão prática";

- a compreensão dessa dinâmica vai além da dimensão material propriamente dita e insere-se na esfera subjetiva e da compreensão do desenvolvimento de estratégias de reprodução que pressupõem um campo de representações a ultrapassarem o domínio da lógica, dos determinismos e das regras.

Os pressupostos acima descritos podem ser percebidos dentro de um conjunto de referências conceituais que podem se complementar. Sendo possível falar em uma fenomenologia constitutiva da produção do hábitat por meio dos assentamentos humanos, as reflexões de Campos \& Ferreira, valendose dos conceitos de Heidegger, permitem qualificar a reflexão ora em curso.

"O homem é um 'ser-no-mundo' (HEIDEGGER, 1995) e o meio ambiente construído é uma concreção da cultura (HEIDEGGER, 1951), dentro da qual a existência humana tem primeiramente seu lugar. Sendo uma forma da expressão humana, o ambiente construído é 'congruente com os tipos de organização social da cultura, da qual ele emerge como concreção."' (SOUZA, 1998) Dessa maneira, "não habitamos porque construímos, mas construímos e temos construido porque habitamos, isto é, enquanto somos habitantes" (CAMPOS; FERREIRA, 2002, p. 107).

Nessa perspectiva de compreensão da relação homem-meio ambiente pode-se pensar como Tassara e Rabinovich (2001, p. 213), para os quais uma intervenção ambiental deva ser fundamentada nas aspirações de transformação assentadas sobre a vivência das pessoas no urbano. Isso porque, segundo Tassara e Rabinovich, "As formas de ocupação favoreceram fortemente $o$ 
enraizamento através das relações por ela propiciadas com as redes de sociabilidade por influenciar profundamente a constituição de específicas comunidades de destino (BOSI, 1995): quer por relações eventuais de vizinhança como espaço de convivência; quer pela possibilidade de compartilhar um processo de ocupação que se dá pari passu com as transformações identitárias, quer ainda, pela não possibilidade de estabelecimento de identidades nem por vizinhança nem por história compartilhada, ficando então restrita ao próprio núcleo familiar ou residencial" (TASSARA; RABINOVICH, 2001, p. 264).

Partindo-se desses pressupostos, torna-se possível abordar a questão da produção de assentamentos humanos, geradores de condições de inclusão precária, valendo-se de formas de investigação que permitam construir uma análise a possibilitar refletir sobre a produção desses assentamentos sob um enfoque multidimensional. Significa entender se o ideal de urbanidade, cuja gênese se situa na condição de cidadão que contém os hábitos de citadino, pode ser compreendido quando uma parcela significativa das populações de aglomerados urbanos e regiões metropolitanas vivem sob condições que não se enquadram dentro dos parâmetros da modernidade e das normativas urbanísticas vigentes.

\section{REFERÊNCIAS}

AMARAL, Rita. Povo-de-santo, povo de festa: 0 estilo de vida dos adeptos do candomblé paulista. 1992. 334 f. Dissertação (Mestrado) - Faculdade de Filosofia, Ciências e Letras da Universidade de São Paulo, Universidade de São Paulo, São Paulo, 1992.

AUGE, Marc. A construção do mundo. Lisboa: Edições 70, 2000.

BOURDIEU, Pierre. A economia das trocas simbólicas. São Paulo: Perspectiva, 1999.

___. A miséria do mundo. Petrópolis: Vozes, 1997.

_-_. Razões práticas: sobre a teoria da ação. Tradução de Mariza Corrêa. 4. ed. Campinas: Papirus, 1996.

Stratégies de reproduction et modes de domination. Actes de la Recherche en Sciences Sociale, Paris, v. 105, p. 3-12, 1994.

CAMPOS, Paulo M. E. Souza; FERREIRA, Renato C. Imagem mental e representação social na arquitetura: investigação conceitual a partir de um estudo de caso. In: DEL RIO, Vicente; DUARTE, Cristiane Rose; RHEIWGANTZ, Paulo Afonso. Projeto do lugar: colaboração entre psicologia, arquitetura e urbanismo. Rio de Janeiro: Contra Capa/PROARQ, 2002 (Coleção PROARQ).

GUATTARI, Félix; ROLNIK, Suely. Micropolítica: cartografias do desejo. Rio de Janeiro: Vozes, 2005.

JODELET, Denise. A cidade e a memória. In: DEL RIO, Vicente; DUARTE, Cristiane Rose; RHEINGANTZ, Paulo Afonso. Projeto do lugar: colaboração entre psicologia, arquitetura e urbanismo. Rio de Janeiro: Contra Capa, 2002 (Coleção PROARQ).

KOWARICK, Lúcio; SPOSATI, Aldaíza; VERAS, Maura P. Bicudo. Por uma sociologia da exclusão social. São Paulo: EDCU, 1999.

MARICATO, Ermínia. As idéias fora do lugar e o lugar fora das idéias. Planejamento urbano no Brasil. In: ARANTES, Otília; VAINER, Carlos; MARICATO Ermínia. A cidade do pensamento único: desmanchando consensos. Petrópolis: Vozes, 2000.

MICELI, Sergio. A força do sentido. In: BOURDIEU, Pierre. A economia das trocas simbólicas. São Paulo: Perspectiva, 1999.

ORTIZ, Renato. (Org.). Pierre Bourdieu: sociologia. São Paulo: Ática. 
PAOLIELLO, Renata Medeiros. A dimensão social da paisagem. 2000. Texto apresentado na disciplina AUT-816. Faculdade de Arquitetura e Urbanismo, Universidade de São Paulo, São Paulo, 2000.

PINTO, Louis. Pierre Bourdieu e a teoria do mundo social. Tradução de Luiz Alberto Monjardim. Rio de Janeiro: FGV, 2000.

RHEINGANTZ, Paulo Afonso. Projeto do lugar: colaboração entre psicologia, arquitetura e urbanismo. Rio de Janeiro: Contra Capa, 2002 (Coleção PROARQ).

SANTOS, Boaventura de Souza. Pela mão de Alice: o social e o político na pós-modernidade. 11. ed. São Paulo: Cortez, 2006.

TASSARA, Eda T. de Oliveira; RABINOVICH, Elaine P. A invenção do urbano e o poético: uma cartografia afetiva - estudo sobre o bairro paulistano da Barra Funda. In: TASSARA, Eda T. de Oliveira (Org.). Panoramas interdisciplinares para uma psicologia ambiental do urbano. São Paulo: Educ/Fapesp, 2001.

VELHO, Gilberto (Org.). Antropologia urbana: cultura e sociedade no Brasil e em Portugal. Rio de Janeiro: Jorge Zahar, 1999.

\section{Nota do Editor}

Data de submissão: maio 2010

Aprovação: dezembro 2010

\section{Paulo Romano Reschilian}

Doutor em Arquitetura e Urbanismo pela FAUUSP, docente e pesquisador do Instituto de Pesquisa e Desenvolvimento - Universidade do Vale do Paraíba, docente do Departamento de Arquitetura da Universidade de Taubaté.

Universidade do Vale do Paraíba - Campus Urbanova, Instituto de Pesquisa e Desenvolvimento.

Avenida Shishima Hifume, 2911. Urbanova

12244-000 - Sao José dos Campos, SP

(12) 3947-11-27

paromano@uol.com.br 